\title{
Correlation between rheological properties and capillary fixation for modelling creams
}

\author{
Lara Brogni Demoliner'1, Lucas Dall Agnol'², Suzana Bittencourt Zanotti', Fernanda Trindade \\ Gonzalez Dias ${ }^{3}$, Valeria Weiss Angeli ${ }^{1}$, Otavio Bianchi' ${ }^{2,3^{*}}$
}

\begin{abstract}
${ }^{1}$ University of Caxias do Sul (UCS), Caxias do Sul, Brazil, ${ }^{2}$ Health Sciences Graduate Program, University of Caxias do Sul (UCS), Caxias do Sul, Brazil, ${ }^{3}$ Materials Science Graduate Program (PGMAT), University of Caxias do Sul (UCS), Caxias do Sul, Brazil
\end{abstract}

\begin{abstract}
The Brazilian male beauty market occupies the second place in world consumption of cosmetics. Among the numerous products consumed by such audience is the capillary fixation mask, which is mainly composed by fixatives. These additives act on stabilizing the cosmetic emulsion, protecting the hair against moisture and also increasing the intensity of hair fixation. In this work, three formulations for modelling creams were prepared by different concentrations of the fixatives Styleze ${ }^{\mathrm{TM}} \mathrm{W} 20$ and PVP K90 and their properties characterized by physicochemical, rheological and sensory analysis. The capillary masks produced were stable oil-in-water $(\mathrm{O} / \mathrm{W})$ emulsions with uniform droplets of 2.05$2.82 \mu \mathrm{m}$ sizes and pseudoplastic thixotropic behavior $(0.19<\mathrm{n}<0.26)$. It was possible to correlate the increased concentration of PVP K90 to a greater thixotropy and an improved yarn fixation, despite the worsening in the spreadability of the formulations. These results suggest properly conducted rheological measurements can contribute to the prediction of the emulsion's sensory properties, which can save time and funds on the development of new cosmetics.
\end{abstract}

Keywords: Rheology. Microscopy. $N$-vinyl-2-pyrrolidone. Polyquaternium-55. Modelling cream/ physicochemical properties. Cosmetics.

\section{INTRODUCTION}

According to Brazilian Cosmetic, Toiletry and Fragance Industry (Abihpec), the Brazilian male beauty market is expanding and currently occupies the second place at such cosmetics category consumption in the world (ABIHPEC, 2014). The growth of the sector between the years 1996 to 2013 surpassed that of the other industrial segments. The increase in Brazil's gross domestic product (GDP) is proof of such growth: " $9.8 \%$ per year of average growth in the sector against $3.0 \%$ per year of Total GDP and 2.2\% per year of other industrial segments" (Garcillán, 2008; ABIHPEC, 2014). Such audience consumes several cosmetic products, and one of them is the modelling and/or hair fixative cream (Almeida, Bahia, 2003; Correa, 2012).

\footnotetext{
* Correspondence: O. Bianchi. University of Caxias do Sul (UCS). Rua Francisco Getúlio Vargas, 1130, Bloco V/Sala 301 Petrópolis district, 95070-560, Caxias do Sul - RS, Brasil. Phone: +55 5432182100 extension 2088, Fax: +555432182159. E-mail: obianchi@ucs.br or otavio.bianchi@gmail.com
}

Today's hair-styling formulations should meet the properties of humidity resistance and stiffness, combined with the sensory attributes of shine enhancement and good spreadability through hair (Lochhead, 2007). Emulsions used in personal care application, both water-in-oil $(\mathrm{W} / \mathrm{O})$ and oil-in-water $(\mathrm{O} / \mathrm{W})$ types, need to present the right consistency (rheology) for use, long-term physical stability (2-3 years) under varying conditions of temperature and transportation and functional additives to ensure satisfactory performance (Oliveira et al., 2004; Estanqueiro et al., 2014).

One of the main components of modelling creams are the modelling additives and/or fasteners, which are responsible for creating a layer that will act as a barrier to physically protect the hair against moisture and also allow the user to style it as desired. An example of an agent used to promote hair strands conditioning is the Polyquaternium-55 marketed as Styleze ${ }^{\mathrm{TM}}$ W20, which consists of an aqueous solution (20wt.\%) of a quaternary ammonium salt. It is used as the cationic surfactant of the 
emulsion due to the presence of a polar group (Surh et al., 2007). Another example is the $N$-vinyl-2-pyrrolidone (PVP) homopolymer, marketed as PVP K30 or PVP K90, whose differences consist on their average molecular weight (90.000 and 1.300.000 Daltons). The PVP is compatible with hydrophobic and hydrophilic polymers, and this includes hygroscopic amorphous white powder soluble in water and some organic solvents (Halal, 2011; Correa, 2012).

The purpose of using humectant gels and emulsions for skin or hair care is to prevent the cosmetic system from losing water, thus avoiding the formation of a plasticized layer on the cream surface (Milan et al., 2007; Halal, 2011). Therefore, the greater the humectant concentration used, the greater will be the moist effect provided to the hair. The rheological behavior of cosmetic products is one of the most important features not only from technical but also from the aesthetic point of view (Korać, Krajišnik, Milić, 2016). The type and amount of humectant agent, as well as the lipid composition, emulsifier type and concentration, particle droplet size and preparation methods directly affect the rheological properties of such emulsions (Corrêa et al., 2005; Milan et al., 2007; Frange, Garcia, 2009; Arandas, Rigon, Costa, 2013).

The addition of thixotropic agents to an emulsion favors the increase of viscosity and therefore prolongs its shelf life, avoiding the undesirable phenomena of sedimentation. The preparation becomes fluid when subjected to external pressure, being quickly spread on the target region and its viscosity is restored once pressure ceases, thus preventing an improperly draining away of the product (Aulton, 2005; Corrêa et al. 2005; Milan et al., 2007; Tadros, 2013). The flow index indicates the rheological behavior of the fluid, usually pseudoplastic for cosmetic emulsions, whereas the system thixotropy is characterized by the existence of a hysteresis area when a particular external force is applied. The increasing pressure or stirring does not increase the flow velocity, but the viscosity changes as the shear rate increases (Schramm, 2006; Lee, Moturi, Lee, 2009; Tadros, 2013). This means the rheological characteristics of the fluid assist the formulator in the development and production process to avoid and/ or prevent unwanted changes ensuring the stability and effectiveness of the cosmetic product (Schramm, 2006; Lee, Moturi, Lee, 2009; Gonçalves, Srebernich, Souza, 2011; Tadros, 2013; Damasceno et al., 2016).

In the development of a cosmetic product, both rheological and sensory approaches are not mutually independent, but coupled. A close coupling between the rheological and sensory parameters can save time and money consuming sensory assessment by fast instrumental rheological analysis (Moravkova, Filip, 2014). Sensory analysis is subjective and present several drawbacks. If close relations between the individual sensory parameters and experimental rheological parameters determined by the models are found, then it will be possible to substitute the sensory analysis by the rheological measurements (Moravkova, Filip, 2014).

In this context, the aim of this work is to prepare modelling cream formulations by varying the concentration of the fixing agents to evaluate the interdependence between rheological properties and capillary fixation capacity of the emulsifiable systems, the size of the drops, the spreadability and the characteristics such as increased capillary oiliness and softness.

\section{MATERIAL AND METHODS}

\section{Preparation of capillary fixating masks}

Aiming to find the relationship between the rheological parameters the type and the concentration of the agents responsible for hair fixation, three emulsion formulations (A, B and C) were delineated varying the amount of the fixing agents PVP K90 (5.77 wt.\%-A, 11.55 wt.\%-B and 8.66 wt.\%-C) and Styleze ${ }^{\mathrm{TM}} \mathrm{W} 20$ (10.0 wt.\%-A, 5.0 wt.\%-B and 7.5 wt.\%-C), according to the Table I.

The masks (100 $\mathrm{g}$ of each sample) were prepared according to the literature (Almeida, Bahia, 2003; Almeida, Teixeira, Koester, 2008). The emulsions were prepared by heating the aqueous and oily phases separately at $70^{\circ} \mathrm{C}$. When the two phases were at the same temperature, the aqueous phase was slowly poured into the oily phase, and the system was kept under vigorous agitation (Ultra-Turrax ${ }^{\circledR} \mathrm{T} 25$ ) up to $80^{\circ} \mathrm{C}$. The phases were then mixed using an Electrolux mixer (Model IBE20) until cooling (Silva, Soares, 1996; Correa, 2012). After cooling, the essence and the preservatives (Germall Plus ${ }^{\mathrm{TM}}$ Líquid) were added to the emulsion. The obtained formulations were stored at room temperature (Estanqueiro et al., 2014). Figure 1 summarizes the methodology used in this study. Before analysis and characterization, the formulations were preliminarily centrifuged to evaluate their stability. Only the samples that did not present phase separation were considered for the study. Any instability pointed to by this test signaled the need for product reformulation.

\section{Stability of samples}

The first stage of developing a cosmetic product consists in observing whether or not there are any 
Correlation between rheological properties and capillary fixation for modelling creams

TABLE I - Composition of the fixing masks A, B and C adapted from (Corrêa et al., 2005; Brandão, 2009; Correa, 2012)

\begin{tabular}{|c|c|c|c|c|}
\hline COMPONENTS & INCI $^{1}$ & $\mathbf{A}^{2}$ & $\mathbf{B}^{2}$ & $\mathrm{C}^{2}$ \\
\hline Germall Plus ${ }^{\mathrm{TM}}$ Liquid & $\begin{array}{c}\text { Propylene Glycol (and) } \\
\text { Diazolidynil Urea (and) } \\
\text { Iodopropynyl Butylcarbamate }\end{array}$ & 0.50 & 0.50 & 0.50 \\
\hline Quasar fragrance $n^{\circ} 36$ & Fragrance & 3 drops & 3 drops & 3 drops \\
\hline \multicolumn{5}{|l|}{ AQUEOUS PHASE } \\
\hline Distilled water & Water (aqua) & 55.77 & 54.99 & 55.38 \\
\hline EDTA Na & Disodium EDTA & 0.11 & 0.11 & 0.11 \\
\hline PVP K90 & PVP & $5.77^{3}$ & $11.55^{3}$ & $8.66^{3}$ \\
\hline Styleze $^{\mathrm{TM}} \mathrm{W} 20$ & Polyquaternium-55 & 10.00 & 5.00 & 7.50 \\
\hline Glycerin & Glycerin & 2.00 & 2.00 & 2.00 \\
\hline Propylene Glycol & Propylene Glycol & 5.00 & 5.00 & 5.00 \\
\hline Tween $^{\mathrm{TM}} 20$ & Polysorbate-20 & 2.30 & 2.30 & 2.30 \\
\hline Polyquaternium-7 & Polyquaternium-7 & 0.50 & 0.50 & 0.50 \\
\hline \multicolumn{5}{|l|}{ OLEOUS PHASE } \\
\hline Glyceryl Monostearate & Glyceryl Stearate & 2.50 & 2.50 & 2.50 \\
\hline BHT & BHT & 0.05 & 0.05 & 0.05 \\
\hline Shea Butter & Shea Butter & 0.50 & 0.50 & 0.50 \\
\hline Cetearyl Alcohol & Cetearyl Alcohol & 5.00 & 5.00 & 5.00 \\
\hline Cetostearyl Alcohol Ethoxylate & Ceteareth-20 & 3.00 & 3.00 & 3.00 \\
\hline Isopropyl Myristate & Isopropyl Myristate & 3.00 & 3.00 & 3.00 \\
\hline Beeswax & Beeswax & 4.00 & 4.00 & 4.00 \\
\hline
\end{tabular}

(1) International Nomenclature of Cosmetic Ingredients; (2) concentrations in weight percent; (3) concentration calculated taking into account the $86.6 \%$ purity of the compound.

changes in the physicochemical properties of the base formula (Korać, Krajišnik, Milić, 2016). The emulsions were submitted to an accelerated stability study by centrifugation after twenty-four hours of their manipulation. In conical tubes for centrifugal testing (Model PK131 ALC Multispeed Centrifuge) $2.0 \mathrm{~g}$ of each sample was added and subjected to a cycle of $3000 \mathrm{rpm}$ for thirty minutes at room temperature. Only the samples that did not present phase separation followed the subsequent efficacy tests.

\section{Determination of emulsion type}

The Dye-Solubility Test allows the identification of the type of emulsion produced: water-in-oil (W/O) or oilin-water $(\mathrm{O} / \mathrm{W})$. This method consists in the dilution of 0.5 $\mathrm{g}$ of sample in $10 \mathrm{~mL}$ of a hydrophilic solution containing blue dye for cosmetic use. As a control, $0.5 \mathrm{~g}$ vaseline was also diluted in an equal volume of dye solution. If the blend shows an inhomogeneous and coagulated appearance, the result is a W/O type emulsion; whereas, if the mixture displays a uniform color, the result is an $\mathrm{O} / \mathrm{W}$ emulsion (Alfred, Pilar, Chun, 1993; Khan et al., 2011).

\section{Emulsion droplet size determination}

The $\mathrm{O} / \mathrm{W}$ emulsion droplet size determination was optimized by optical microscopy. The samples $(0.1 \mu \mathrm{L})$ were placed on glass microscope slides forming a thin layer. These were covered with coverslips and analyzed under transmitted light microscopy with 1000-fold magnification (Microscope Zeiss Scope A1) to observe the homogeneity of the emulsion and determine the size of the dispersed droplets. The size of the dispersed phase in the samples was measured using freeware software Image Tool version 1.28 (CMEIAS-IT 1.28). The average number diameter $\left(D_{n}\right)$ and average weight diameter $\left(D_{w}\right)$, the volumetric average diameter $\left(\mathrm{D}_{\mathrm{v}}\right)$ and the polydispersity $\left(D_{w} / D_{n}\right)$ of the systems were determined according to literature (Bondan, Bianchi, 2015; Bondan et al., 2016):

$$
D_{n}=\frac{\sum N_{i} D_{i}}{\sum N_{i}}
$$




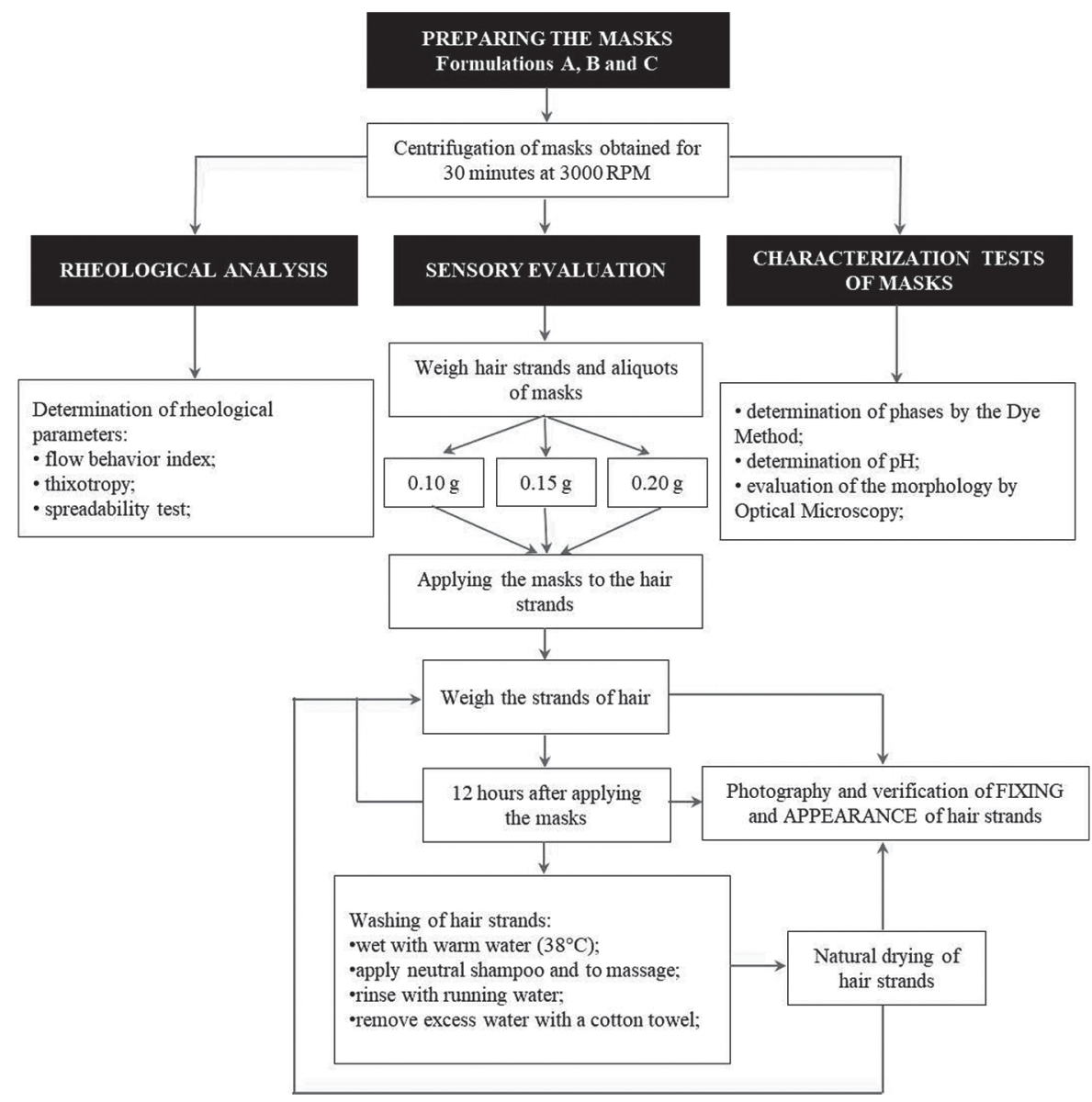

FIGURE 1 - Summary of the methodology.

$$
\begin{gathered}
\boldsymbol{D}_{w}=\frac{\sum \boldsymbol{N}_{i} \boldsymbol{D}_{i}^{2}}{\sum \boldsymbol{N}_{i} \boldsymbol{D}_{i}} \\
\boldsymbol{D}_{v}=\frac{\sum \boldsymbol{N}_{\boldsymbol{i}} \boldsymbol{D}_{i}^{4}}{\sum \boldsymbol{N}_{\boldsymbol{i}} \boldsymbol{D}_{i}^{3}}
\end{gathered}
$$

where $N_{i}$ is the number of drops measured and $D_{i}$ is the drop diameter $[\mu \mathrm{m}]$.

\section{Determination of $\mathrm{pH}$}

For $\mathrm{pH}$ determination, the samples were dispersed in distilled water $(1: 10 \mathrm{w} / \mathrm{v})$, homogenized and subjected to reading at $23{ }^{\circ} \mathrm{C}$ in a pH-meter (Micronal - model B474), previously calibrated with standard solutions of $\mathrm{pH} 7.0$ and 4.0. The results correspond to the average of three determinations with the respective standard deviations.

\section{Rheological tests}

Determination of rheological profiles of emulsions

Rheological analysis has also been used to predict the behavior of emulsions and provide information to improve stability and general performance. The experiments were performed on an Anton Paar Rheolab MCR 102 rheometer (Graz, Austria) using cone/plate geometry (diameter $50 \mathrm{~mm}$, angle $1^{\circ}$ ). Continuous flow test for the three formulations was performed at $25^{\circ} \mathrm{C}$ (capillary wire surface temperature). During the continual measurements, shear rate was increased in the range $10^{-3}-1000 \mathrm{~s}^{-1}$ (upward curve) and decreased in range $1000-10^{-3} \mathrm{~s}^{-1}$ (downward curve). Thus it was possible to determine the rheological profile of the samples, and its hysteresis, typically characteristic of thixotropic fluids.

\section{Spreadability of formulations}

Spreading is a determinant textural attribute that governs the performance of the product during its application (Estanqueiro et al., 2014; Montenegro et al., 2015). The equipment used for spreadability evaluation consists of an acrylic circular mold plate (diameter $=20$ $\mathrm{cm}$; thickness $=0.2 \mathrm{~cm}$ ) with the center hole of $12 \mathrm{~mm}$ in diameter fixed temporarily on a glass support plate $(20 \mathrm{~cm} \times 20 \mathrm{~cm})$ positioned on a millimeter scale and a 
light source. After the sample is introduced through the orifice of the mold plate with leveling of the surface with a spatula, the mold plate was carefully removed, and a glass plate of known weight was placed on the sample (i). After one minute, the diameters readings were made in two opposite positions (for the mean diameter determination). The procedure was repeated with the placement of new plates at one-minute intervals after the area had been covered, and the weight of each added plate was recorded until constant values were obtained. The spreadability $\left(\mathrm{E}_{\mathrm{i}}\right)$ was determined at $23{ }^{\circ} \mathrm{C}$ according to equation 4 (Zanin et al., 2001).

$$
E_{i}=d^{2} \frac{\pi}{4}
$$

where $E_{i}$ is the spreadability of the sample to the mass of the plate $i\left[\mathrm{~mm}^{2}\right]$ and $d$ is the mean diameter of spreading of the sample [mm].

\section{Sensory evaluation by visual comparison}

The formulations were applied to previously cleaned and dried natural hair strands. Each of the hair locks had the mass measured on an analytical balance (GEHAKA BG 200; São Paulo, Brazil) before and after application of the creams. The washing of the hair locks occurred to reproduce the traditional washing of the hair during bathing: the strands of hair were wet with warm water $\left(38^{\circ} \mathrm{C}\right)$ followed by application of neutral shampoo (Di Hellen) and rinsed. The excess water was removed with the aid of a cotton towel for subsequent natural drying of hair strands.

Each of the three formulations (at 0.10, 0.15 and $0.20 \mathrm{~g}$ weights) were applied to the cleaned hair strands. The permanence time of masks on the hair (12 hours) reproduces their use by consumers who implement the product in the morning and remove it at night. The amount of applied product was considered for the evaluation concerning the fixability softness and appearance of hair strands (gloss oiliness). The samples were also classified concerning the residuals left after removing the creams with a subsequent washing and another weighing of the hair strands.

\section{RESULTS AND DISCUSSION}

Cosmetics are required to be highly stable over a long period (Estanqueiro et al., 2014; Moravkova, Filip, 2014; Korać, Krajišnik, Milić, 2016). The results of stability testing provide information about the emulsion quality as well as its shelf-life. The centrifugation test simulates an increase in the gravity force accelerating the movement of particles and anticipating possible physical-chemical instabilities of the formulation (phase separation, precipitation or coalescence). The absence of such changes after centrifugation means the emulsion is physically stable under normal gravity conditions (Tadros, 2013; ABIHPEC, 2014). All formulations produced were approved in this experiment, meaning little physicalchemical changes in its systems (Surh et al., 2007; Tadros, 2013).

The dye test indicated that the capillary masks formulated are emulsified oil-in-water systems $(\mathrm{O} / \mathrm{W})$ since all samples showed continuous and uniform coloration after dilution in an aqueous solution containing blue dye. The Vaseline-dye solution mixture showed heterogeneous appearance due to the non-solubilization of its hydrophobic molecules in the dye, as observed in Figure 2 ( $2 \mathrm{a}$ and $2 \mathrm{~b}$ ). Similar behavior was observed on formulations $\mathrm{B}$ and $\mathrm{C}$. Obtaining an $\mathrm{O} / \mathrm{W}$ emulsion is related to the use of surfactants with a hydrophilic portion much larger than the lipophilic portion (water-oil ratio).
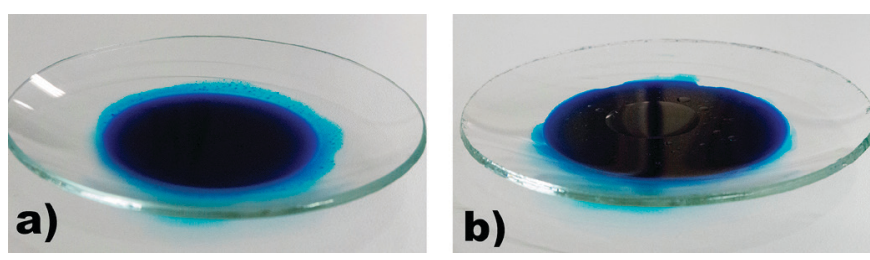

FIGURE 2 - Dye Method results; (a) dilution of samples A; (b) Example of the mixture of vaseline in the coloring solution for sample A.

The intensity and the time of agitation during emulsion's preparation are variables that directly influence on the size of the droplets. The interfacial tension is higher when the droplets are smaller (Surh et al., 2007). As shown in Figure 3 the samples had dispersed oil droplets in the aqueous phase. All samples presented homogeneous globules, which favored the stability of the formulations.

The droplet size estimate was performed through the average diameter of a hundred drops, as shown in Table II. The droplet size uniformity of the three samples analyzed was confirmed by the polydispersity value close to 1 . Sample A showed a smaller droplet size $(\sim 2.05 \mu \mathrm{m})$ in the dispersed phase when compared to samples $\mathrm{B}(\sim 2.75 \mu \mathrm{m})$ and $\mathrm{C}(\sim 2.82 \mu \mathrm{m})$. Several factors may influence the droplet size of an emulsion, like the agitation time and temperature during preparation (Correa, 2012). The droplet size reduction is related to the interfacial tension reduction, which can be promoted by a higher amount of cationic surfactant in the formulation (Estanqueiro et al., 

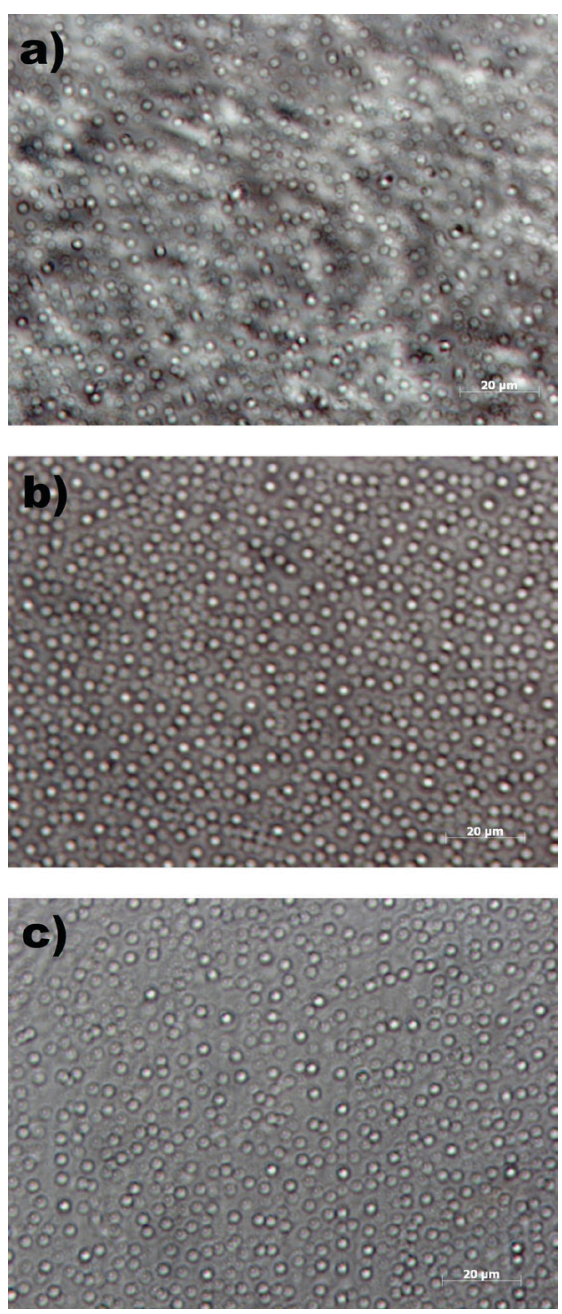

FIGURE 3 - Optical microscopy with transmitted light and 1000x magnification for formulations A, B and C.

2014). According to the Taylor's law, the lower the interfacial tension, the lower the dispersed particle size (Taylor, 1934).

The $\mathrm{pH}$ of the formulations must be compatible with the $\mathrm{pH}$ of hair, thus avoiding any damage to hair fibers. Changes in the product's $\mathrm{pH}$ during storage signal emulsion instability, which influences the active substances effectiveness. The $\mathrm{pH}$ is a determining factor in choosing the constituents of the formulation (Frange, Garcia, 2009; Leonardi, Spers, 2015). The masks should facilitate hairstyle, providing shine and softness to the hair and not damaging it. Values of $\mathrm{pH}$ between 4.0 and 5.5 are recommended (Frange, Garcia, 2009; Leonardi, Spers, 2015), and all the three formulations have met such requirement $(4.62 ; 4.79$ and 4.63 for samples $\mathrm{A}, \mathrm{B}$ and $\mathrm{C}$, respectively).

Changes in the rheological properties of emulsions show problems in the physical-chemical stability of the final product. The decrease in viscosity values indicates destabilization of the emulsion's structure since the apparent viscosity is related to the physical stability of the formulation (Aulton, 2005; Surh et al., 2007; Tadros, 2013). Figure 4 shows the hysteresis loop curves for samples A (Figure 4a), B (Figure 4b) and C (Figure 4c) whose internal areas indicate the energy required to break the thixotropic structures of the materials analyzed. All emulsions showed a pseudoplastic thixotropic behavior. The thixotropic characteristic is considered desirable for topical preparations as it improves spreading of the product (Estanqueiro et al., 2014; Montenegro et al., 2015). The molecules are oriented in the flow direction, resulting in stretching and destroying interactions between species (ionic. dipole and hydrogen), which stabilize its structure. Thus reduction of the fluid viscosity occurs. By removing the shear rate, the molecules gradually return to their original state by Brownian motion (Steffe, 1996; Surh et al., 2007; Tadros, 2013). The faster the restructuring, the higher the material's thixotropy and the smaller its hysteresis area.

A relationship between emulsion thixotropic behavior and emulsion composition can be established by comparing the rheograms of $\mathrm{O} / \mathrm{W}$ emulsions in

TABLE II -Droplet sizes parameters of formulations A, B and C

\begin{tabular}{lccc}
\hline \multirow{2}{*}{ Droplet sizes parameters } & \multicolumn{3}{c}{ Sample } \\
\cline { 2 - 4 } & A & B & C \\
\hline Number average diameter $(\mu \mathrm{m})$ & 2.08 & 2.79 & 2.77 \\
Weight average diameter $(\mu \mathrm{m})$ & 2.10 & 2.81 & 2.79 \\
Volume average diameter $(\mu \mathrm{m})$ & 2.16 & 2.80 & 2.83 \\
Polydispersivity & 1.012 & 1.008 & 1.007 \\
Minimum $(\mu \mathrm{m})$ & 1.62 & 2.30 & 2.21 \\
Maximum $(\mu \mathrm{m})$ & 2.83 & 3.60 & 3.42 \\
Mean \pm standard deviation $(\mu \mathrm{m})$ & $2.05 \pm 0.20$ & $2.75 \pm 0.20$ & $2.82 \pm 0.23$ \\
\hline
\end{tabular}


Figure 4. The sample B presented lower thixotropy loop area when compared to the other samples. According to (Aulton, 2005), the emulsions containing PVP K90 show pseudoplastic behavior with the thixotropic response. Thus, the increased concentration of that polymer results in reduction of thixotropy behavior. The consistency index (k) determined from the application of the power-law model $\left(\eta=k \gamma^{\mathrm{n}-1}\right)$ relates to the viscosity of the material at a particular shear rate. Thus, the higher the value of this index, the more consistent (viscous) is the fluid when compared with fluids with similar values of $n$. On the other hand, its lower value in the second measurement range is related to the intensity of the destruction of the emulsion structure caused by the shear (Lee, Moturi, Lee, 2009). If the shear stress results in the irreversible destruction of the 3-D structures (with the rupture of the intermolecular forces), the droplets flatten, and the surfactants structure around breaks down, causing droplet flocculation, increase in size (Ostwald maturation) and coalescence (Lee Moturi, Lee, 2009; Tadros, 2013).

For systems that do not recover instantly when the shear rate stops, there are two viscosity values (one for each shear rate). The first interval at the upward curve is related to the material viscosity. The second interval at the downward curve represents the viscosity of the ruptured system (Lee, Moturi, Lee, 2009; Tadros, 2013). As observed in Figure 5, the viscosity of the samples reduces as the shear rate increases in the first interval. Because of the thixotropic behavior of the samples, their viscosity values are lower in the second shear interval. Besides, the downward curve was always lower than the upward curve, which means that the system's internal structure recovered faster than it was damaged, reflecting its stability (Chhatbar et al., 2012; Dolz et al., 2000).

The rheological constants (Table III) were obtained by adjusting the data to the Ostwald-de Waele Model (Steffe, 1996; Lee, Moturi, Lee, 2009; Tadros, 2013). For fluids with $n$ closer to 1 , a Newtonian behavior is observed. Fluids with $n$ values close to zero approach the pseudoplastic behavior. Formulations A, B and C showed a higher pseudoplastic behavior (shear thinning) in the first range due to the rupture of intermolecular interactions. Sample A showed the highest value of the consistency index $(k)$. The greater reduction was noted at the second range of shear rates, and this sample demanded more energy to rupture its structure.

Such behavior can be justified by the higher concentration of Styleze ${ }^{\mathrm{TM}}$ W20 compound (10wt.\%) in formulation A. Styleze ${ }^{\mathrm{TM}} \mathrm{W} 20$ has a polar group and a long alkyl chain which provides greater stability in the sample due to strong intermolecular bonds (Wu, 1971).
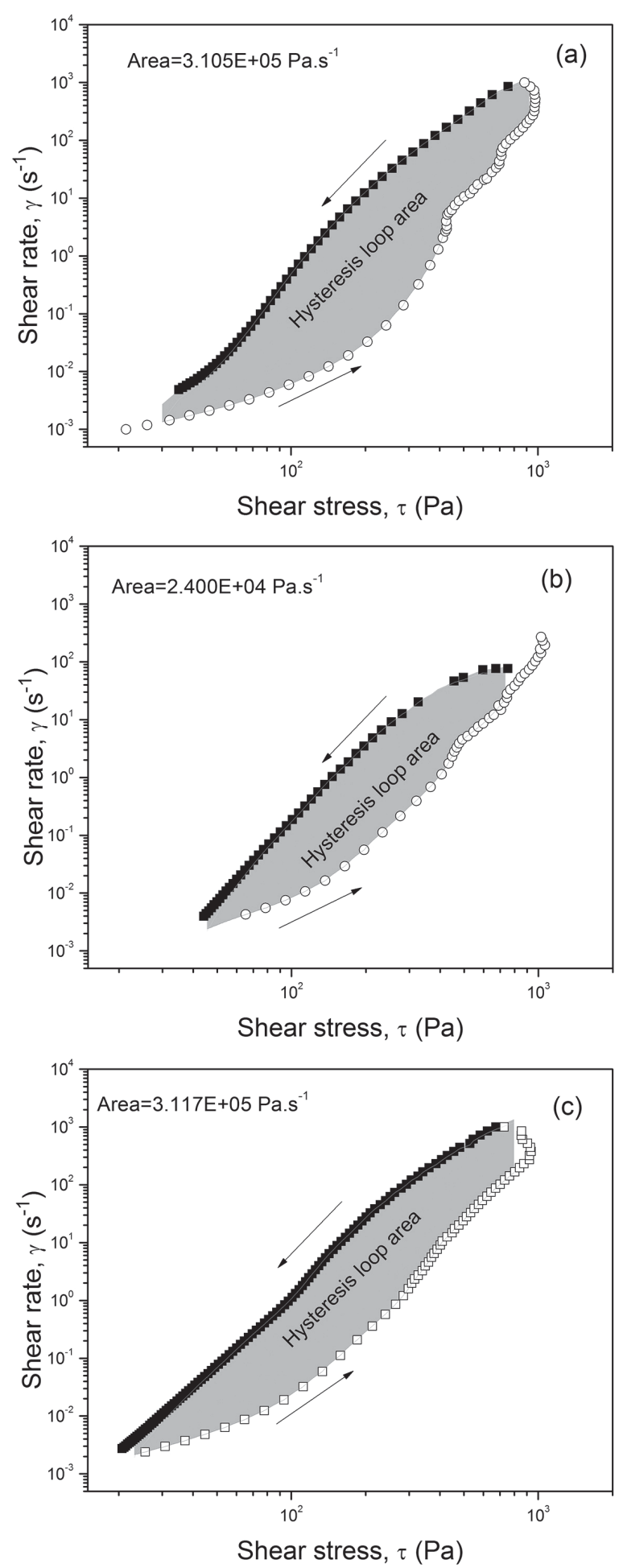

FIGURE 4 - Hysteresis curves for samples A, B and C.

Sample A also showed a smaller drop size than the other samples, which contributed to an interfacial area increase and, consequently to a higher consistency and a lower $n$ value. Concerning sample $B$, a lower hysteresis area is observed, as the shear orientation of the particles occurs in the direction of flow. The intermolecular interactions occur 

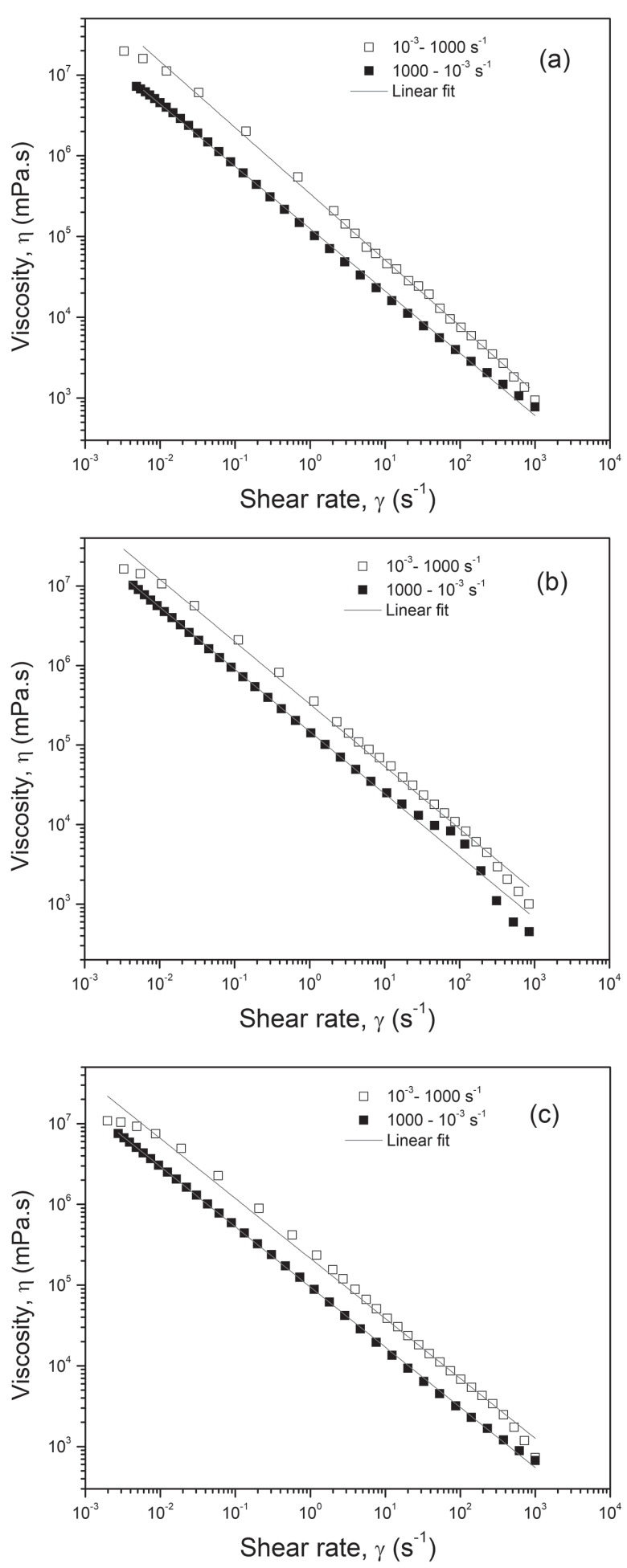

FIGURE 5 - Rheological profiles for samples A, B and C.

in smaller quantities due to the lower concentration of surfactant. The PVP K90 does not have polar groups in its structure; thus the energy to break the structure is smaller. Despite being the least viscous fluid (lower $k$ value), sample $\mathrm{C}$ showed similar hysteresis area than sample A. Thus, a direct relationship between the surfactant amount and the rheological stability of the emulsion can be established, exactly as was evidenced earlier (Taylor, 1934; Wu, 1971).

Figure 6 shows the spreadability area of the formulations results. Usually, this test is performed to compare the spreadability of a new emulsion with that of a similar commercial formulation (Estanqueiro et al., 2014; Montenegro et al., 2015). In this case, samples A, B and $\mathrm{C}$ were compared to each other to identify the influence of the fixating polymers in the formulations (Zanin et al., 2001). Samples A and C showed similar spreadability areas while sample B presented the lowest value because of the thixotropic behavior of the formulation (Plocica, Tal-Figiel, Figiel, 2013; Montenegro et al., 2015). For a higher thixotropic loop area it becomes harder to spread at the same volume, whereas for a lower thixotropy behavior greater spreadability is observed due to weak molecular interactions.

The amount of $0.15 \mathrm{~g}$ of each of the samples was considered ideal to provide the balance between gloss and oiliness residual appearance of plasticized film and fixation after 12 hours of application $(0.10 \mathrm{~g}$ was insufficient to promote hair fixation, and $0.20 \mathrm{~g}$ provided intensification of the results). Only the softness of the hair strands showed no influence according to the amount applied (Table IV).

Brightness is directly related to the oily aspect perceived on the touch, a characteristic to be avoided in a commercial product. After 12 hours of samples having been applied to hair, weighing confirmed the evaporation of the water contained in the formulations. There was a reduction of approximately $50 \%$ of the mass applied on the hair. However, the creams residues that remained on the strands had the appearance of a plasticized film. This seems to be related to the concentration of PVP K90 above $5 \mathrm{wt} . \%$ associated with Styleze ${ }^{\mathrm{TM}} \mathrm{W} 20$. After washing, the hair strands that received the creams were softer than those who did not receive the treatment. Softness and hydration are expected to be promoted by the moisturizing compounds present in the formulations and not by the amount of fixating substances used. This proves that the fixating agent concentration does not interfere with the moisturizing properties of these creams. Approximately $2 \mathrm{wt} . \%$ of sample B has not been removed from the hair strands after washing and drying. Nonetheless, this residue was not observed visually or by touch. Therefore, the influence of increasing the concentration of the PVP K90 with improved hair fixation is inversely proportional to the ease of spreading of the formulations. This observation is in good agreement with rheological results, which means that rheology could be used for sensory properties 
TABLE III - Rheological parameters

\begin{tabular}{lccccc}
\hline Sample & $\begin{array}{c}\text { Hysteresis area } \\
\left(\text { Pa.s }^{-1}\right)\end{array}$ & Interval $\left(\mathbf{s}^{-1}\right)$ & k (Pa.s) & $\boldsymbol{n}$ & $\mathbf{R}$ \\
\hline A & \multirow{2}{*}{310500} & $10^{-3}-1000$ & 331.1 & 0.19 & 0.9985 \\
& $1000-10^{-3}$ & 123.0 & 0.23 & 0.9990 \\
\hline B & \multirow{2}{*}{24000} & $10^{-3}-1000$ & 328.8 & 0.21 & 0.9942 \\
& & $1000-10^{-3}$ & 148.4 & 0.22 & 0.9950 \\
\hline \multirow{2}{*}{311700} & $10^{-3}-1000$ & 213.7 & 0.26 & 0.9972 \\
& & $1000-10^{-3}$ & 94.6 & 0.25 & 0.9996 \\
\hline
\end{tabular}

TABLE IV - Notes after applying masks to hair strands

\begin{tabular}{lccccc}
\hline Sample & Oiliness and Gloss & Plastic Film & Fixation & $\begin{array}{c}\text { Softness when } \\
\text { washing }\end{array}$ & Post-wash softness \\
\hline $\mathrm{A}$ & ++ & + & + & ++ & ++ \\
$\mathrm{B}$ & + & ++ & +++ & +++ & +++ \\
$\mathrm{C}$ & +++ & +++ & ++ & + & + \\
\hline
\end{tabular}

Note: Quantification order: $(+)$ smaller; $(++)$ medium; $(+++)$ larger.

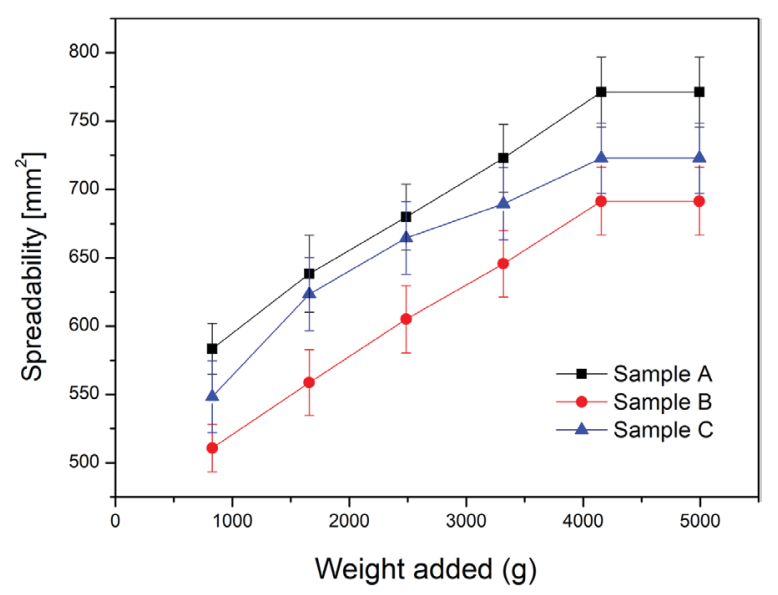

FIGURE 6 - Spreadability profile for formulations.

prediction and emulsions development acceleration in future. Thus, the sensory analysis could be performed at the end of development phase making it less expensive (Montenegro et al., 2015).

\section{CONCLUSION}

The studied formulations presented pseudoplastic behaviors with thixotropic responses, quite common properties in cosmetic preparations. The estimated pseudoplasticity indexes were between 0.19-0.26. However, the consistency of the samples did not show variations depending on the concentration of Styleze ${ }^{\mathrm{TM}}$ W20 or PVP K90. Formulations A, B, and C exhibited average drop sizes of $2.05 \mu \mathrm{m}, 2.75 \mu \mathrm{m}$, and 2.82 $\mu \mathrm{m}$, respectively. All samples had uniform drops with polydispersity close to 1 . The higher fixation strength of the capillary wires is related to increased concentrations of PVP K90 (sample B) presenting smaller thixotropy and area of spreadability. Properly conducted rheological measurements allow for an objective emulsion parameters check. For the modelling creams to be accepted by consumers, adjustments in the formulation must be made to reduce the oily appearance and the plastic aspect provided to hair strands. Understanding the relationship between the physicochemical and sensory properties of emulsions could contribute to predicting the performance of a cosmetic product and choosing the appropriate additives for a successful formulation.

\section{ACKNOWLEDGMENT}

The authors thank the Central Laboratory of Microscopy Prof. Israel Baumvol for using their facilities. The authors also thank Dra. Caroline Luvison and Dr. Edson Francisquetti for help in microscopy and rheological analyses.

\section{REFERENCES}

Associação Brasileira da Indústria de Higiene Pessoal, Perfumaria e Cosméticos. ABIHPEC. Caderno de Tendências 2014-2015, São Paulo: BB Editora; 2014. 
Alfred M, Pilar B, Chun AHC. Physical pharmacy: physical chemical principles in the pharmaceutical sciences. 4th ed. Philadelphia: Lea and Febiger; 1993.

Almeida IF, Bahia MF. Reologia: interesse e aplicações na área cosmético-farmacêutica. Cosmet Toilet. 2003;15(3):96-100.

Almeida ME, Teixeira HF, Koester LS. Preparação de emulsões submicrométricas: aspectos teóricos sobre os métodos empregados na atualidade. Lat Am J Pharm. 2008;27(5):780-8.

Arandas S, Rigon RB, Costa MF. Análise da influência do agente umectante na estabilidade reológica e avaliação de cristais líquidos em formulações cosméticas. Rev Bras Farm. 2013;94(3):199-210.

Aulton ME. Delineamento de formas farmacêuticas. $2^{\mathrm{a}}$ ed. Porto Alegre: Artmed; 2005.

Bondan F, Bianchi O. Effect of dynamic crosslinking on phase morphology and mechanical properties of polyamide 6, 12/ ethylene vinyl acetate copolymer blends. Scientia cum Industria. 2015;3(1):23-8.

Bondan F, Ernzen JR, Amalvy J, Machado AV, Nardi Martins JD, Bianchi O. Influence of dynamic crosslinking on the morphology, crystallization, and dynamic mechanical properties of PA6,12/EVA blends. J Appl Polym Sci. 2016;133(46):12p.

Brandão L. Índex ABC: Ingredientes para a indústria de produtos de higiene pessoal, cosméticos e perfumes. $3^{\mathrm{a}}$ ed. v.2. São Paulo: LMC Pharmabooks; 2009.

Chhatbar MU, Prasad K, Chejara DR, Siddhanta AK. Synthesis of sodium alginate based sprayable new soft gel system. Soft Matter 2012;8(6):1837-1844.

Correa MA. Cosmetologia: ciência e técnica. $1^{a}$ ed. São Paulo: Medfarma; 2012.

Corrêa NM, Camargo Júnior FB, Ignácio RF, Leonardi GR. Avaliação do comportamento reológico de diferentes géis hidrofílicos. Braz J Pharm Sci. 2005;41(1):73-8.

Damasceno GAdB, Silva RMAdC, Fernandes JM, Ostrosky EA, Langassner SMZ, Ferrari M. Use of Opuntia ficus-indica (L.) Mill extracts from Brazilian Caatinga as an alternative of natural moisturizer in cosmetic formulations. Braz J Pharm Sci. 2016;52(3):459-70.
Dolz M, González F, Delegido J, Hernández MJ, Peliccer J. A Time-Dependent Expression for Thixotropic Areas.Application to Aerosil 200 Hydrogels. J Pharm Sci. 2000;89(6):790-797.

Estanqueiro M, Conceição J, Amaral MH, Santos D, Silva JB, Lobo JMS. Characterization and stability studies of emulsion systems containing pumice. Braz J Pharm Sci. 2014;50(2):36169.

Frange RCC, Garcia MTJ. Desenvolvimento de emulsões óleo de oliva / água: avaliação da estabilidade física. Rev Ciênc Farm Básica Apl. 2009;30(3):263-71.

Garcillan MD. Marketing para cosméticos: uma abordagem internacional. São Paulo; 2008.

Gonçalves GMS, Srebernich SM, Souza JAdM. Stability and sensory assessment of emulsions containing propolis extract and/or tocopheryl acetate. Braz J Pharm Sci. 2011;47(3):585-92.

Halal J. Tricologia e a química cosmética capilar. $2^{\mathrm{a}}$ ed. São Paulo: Cengage; 2011.

Khan BA, Akhtar N, Khan HMS, Waseem K, Mahmood T, Rasul A, et al. Basics of pharmaceutical emulsions: A review. Afr J Pharm Pharmacol. 2011;5(25):2715-25.

Korać R, Krajišnik D, Milić J. Sensory and instrumental characterization of fast inverting oil-in-water emulsions for cosmetic application. Int J Cosmet Sci. 2016;38(3):246-56.

Lee $\mathrm{CH}$, Moturi V, Lee Y. Thixotropic property in pharmaceutical formulations. J Controlled Release. 2009;136(2):88-98.

Leonardi GR, Spers VRE. Cosmetologia e empreendedorismo: perspectivas criação novos negócios. São Paulo: Pharmabooks; 2015

Lochhead R. The Use of Polymers in Emulsions. J Cosmet Sci. 2007;58(5):171-221.

Milan ALK, Milão D, Souto AA, Corte TWF. Estudo da hidratação da pele por emulsões cosméticas para xerose e sua estabilidade por reologia. Rev Bras Ciênc Farm. 2007;43(4):649-57.

Montenegro L, Rapisarda L, Ministeri C, Puglisi G. Effects of lipids and emulsifiers on the physicochemical and sensory properties of cosmetic emulsions containing vitamin E. Cosmet. 2015;2:35-47. 
Moravkova T, Filip P. The influence of thickeners on the rheological and sensory properties of cosmetic lotions. Acta Polytech Hung. 2014;11(6):173-86.

Oliveira AGD, Scarpa MV, Correa MA, Flávia L, Cera R. Microemulsões: estrutura e aplicações como sistema de liberação de fármacos. Quím Nova. 2004;27(1):131-8.

Płocica J, Tal-Figiel B, Figiel W. Correlation between rheological studies and organoleptic cosmetic emulsion with lanolin - natural emulsifier. Tech Trans Chem. 2013;1:61-8.

Schramm G. Reologia e reometria - fundamentos teóricos e práticos. São Paulo: Artliber; 2006.

Silva EC, Soares IC. Tecnologia de emulsões. Cosmet Toilet. 1996;8:37-46.

Steffe JF. Rheological methods in food process engineering. 2th ed. Michigan: Freeman Press; 1996.
Surh J, Vladisavljević GT, Mun S, McClements DJ. Preparation and characterization of water/oil and water/oil/water emulsions containing biopolymer-gelled water droplets. J Agric Food Chem. 2007;55(1):175-84.

Tadros TF. Emulsion formation, stability, and rheology, in emulsion formation and stability. Weinheim: Wiley-VCH; 2013.

Taylor GI. The formation of emulsions in definable fields of flow. Math Phys Charact. 1934;146(858):501-23.

Wu S. Calculation of interfacial tension in polymer systems. J Polym Sci, Part C: Polym Symp. 1971;34(1):19-30.

Zanin SMW, Miguel MD, Chimelli M, Dalmaz AC. Parâmetros físicos no estudo da estabilidade das emulsões. Visão Acadêmica. 2001;2(2):47-58.

Received for publication on $05^{\text {th }}$ October 2017 Accepted for publication on $06^{\text {rd }}$ February 2018 